\title{
SELETIVIDADE DO HERBICIDA DICLOSULAM, APLICADO EM PRÉ E PÓS-EMERGÊNCIA EM DIVERSAS CULTIVARES DE CANA-DE- AÇÚCAR.
}

\author{
Martins $^{1}$, D., Velini ${ }^{1}$, E.D., Negrisoli ${ }^{2}$, E., Marchi ${ }^{2}$, S.R. e Silva ${ }^{3}$, J. R.V. \\ ${ }^{1}$ Prof. Dr. Docente do Departamento de Produção Vegetal da FCA/UNESP, Botucatu, SP, 18.603-970; \\ ${ }^{2}$ Eng. Agr ${ }^{\circ}$. M.Sc., Pós-graduação em nível de Doutorado, curso de Agricultura, FCA/UNESP. Botucatu, \\ SP; \\ ${ }^{3}$ Eng. Agr ${ }^{\circ}$, Pós-graduação em nível de Mestrado, curso de Agricultura, FCA/UNESP. Botucatu, SP;
}

\begin{abstract}
RESUMO
O objetivo do presente trabalho foi avaliar a seletividade do herbicida diclosulam aplicado em pré e pós-emergência sob diversas cultivares de soqueira de cana-de-açúcar. O experimento foi instalado no município de Barra Bonita/SP, em um Latossolo Roxo distrófico, utilizando-se onze cultivares distintas de cana-de-açúcar: RB 72 454, RB 82 5336, RB 83 5089, RB 83 5486, RB 85 5035, RB 85 5156, SP 701143 , SP 71 1406, SP 79 1011, SP 801842 e PO 8503. Os tratamentos estudados foram (i) diclosulam a $200 \mathrm{~g} \mathrm{ha}^{-1}$ aplicado em pré-emergência, (ii) diclosulam a $200 \mathrm{~g} \mathrm{ha}^{-1}$ aplicado em pós-emergência e, (iii) uma testemunha sem aplicação de herbicidas. Além da fitointoxicação visual das plantas de cana-de-açúcar, também avaliou-se, por ocasião da colheita, vários parâmetros tecnológicos, como Pol, Brix, fibra e produtivos como diâmetro de colmo, número de colmos, comprimento de colmos e rendimento de colmos e açúcar. Apenas as variedades RB 855035 e RB 855156 apresentaram sintomas visuais de intoxicação provocados pelo herbicida diclosulam aplicado tanto em pré como em pós-emergência, sintomas esses que dissiparam-se no decorrer do ciclo da cultura. As características tecnológicas Pol, fibra e Brix não foram afetadas pela aplicação do herbicida diclosulam.
\end{abstract}

Palavras-chave: Herbicida, fitotoxicidade, Saccharum officinalis

\section{Selectivity of Diclosulam Herbicide Applied in Pre and Post-emergence over Several Sugarcane Cultivars.}

\begin{abstract}
The objective of this study was to evaluate the selectivity of diclosulam applied alone in pre or post-emergence to different sugarcane ratoons. The trial was carried out at Barra Bonita town, Brazil. It was used eleven different sugarcane cultivars, as following: RB 72 454, RB 82 5336, RB 83 5089, RB 83 5486, RB 85 5035, RB 85 5156, SP 70 1143, SP 71 1406, SP 79 1011, SP 801842 e PO 8503. The treatments used were (i) diclosulam at $200 \mathrm{~g} \mathrm{~h}^{-1}$ applied in pre-emergence; (ii) diclosulam at $200 \mathrm{~g}$ $\mathrm{h}^{-1}$ applied in post-emergence; and (iii) and an untreated check. Visual injury evaluations were done after applications. Technologic and productive parameters were analyzed at harvest timing, as Pol, Brix, fiber, straw diameter, straw number, straw length, straw and sugar yield. Only the cultivars RB 855035 and RB 855156 showed visual symptoms of intoxication provided by diclosulam in both applications pre or post-emergence. The symptoms disappeared completely during the sugarcane cycle. The technologic characteristics as Pol, fiber and Brix were not influenced by the diclosulam herbicide.
\end{abstract}


Key words - Herbicides, injury, Saccharum officinalis

\section{INTRODUÇÃO}

O diclosulam (N-[2,6-diclorofenil]-5-etoxi-7-fluoro(1,2,4)triazolo-[1,5c]pirimidina-2-sulfonamida) é um herbicida do grupo químico triazolo pirimidina sulfonanilidas indicado para o controle de dicotiledôneas em pré-semeadura incorporada ou em pré-emergência na cultura da soja. Este composto atua inibindo a enzima acetolactato sintase (ALS) a qual é essencial para a síntese dos aminoácidos valina, leucina e isoleucina (Rodrigues e Almeida, 1998). Apresenta amplo expectro de controle como latifolicida, sendo que também pode promover a supressão do crescimento de algumas gramíneas, com Cenchrus echinatus, Brachiaria plantaginea, Brachiaria decumbens e Digitaria horizontalis. Além disso, trabalho de campo conduzido por Constantin et al. (2000a) comprovou que o herbicida diclosulam também apresenta boa performance no controle de ciperáceas, desde de que aplicado em doses superiores a $150 \mathrm{~g} \mathrm{ha}^{-1}$. Desse modo, o herbicida diclosulam apresenta bom potencial para as áreas cultivadas com cana-de-açúcar, embora ainda não haja registro definitivo de utilização para esta cultura.

$\mathrm{Na}$ literatura, ainda, são raros os herbicidas que reportam o comportamento diferencial de genótipos das mais variadas culturas em relação ao herbicida diclosulam. São exemplos de estudos que envolveram análises de seletividade da cultura da canade-açúcar ao herbicida diclosulam os trabalhos desenvolvidos por Constantin et al. (2000a) e Constantin et al. (2000b).

Compreende-se por seletividade a capacidade de um determinado herbicida em eliminar as plantas daninhas que se encontram em uma cultura sem reduzir-lhe a produtividade. Torna-se evidente que a seletividade não pode ser determinada apenas pela simples verificação de sintomas visuais de intoxicação. Existe a necessidade de avaliar os efeitos de tais sintomas visualmente detectáveis e de outros não evidentes, como o crescimento e produtividade da cultura.

Para um herbicida ser recomendado de forma segura para uma determinada cultura, este deve demonstrar seletividade às variedades mais comuns da mesma. A rápida renovação dos genótipos de cana-de-açúcar em uso torna o trabalho de avaliação da sensibilidade de novas cultivares praticamente contínuo e deveria ser realizado indistintamente tanto para herbicidas novos quanto para os tradicionalmente utilizados na cultura. Este trabalho teve por objetivo avaliar a seletividade do herbicida diclosulam aplicado de forma isolada em pré e em pós-emergência sobre diversas cultivares de cana-de-açúcar.

\section{MATERIAL E MÉTODOS}

O experimento foi conduzido na fazenda Quebra Pote, pertencente à Usina da Barra, no município de Barra Bonita/SP, em um solo classificado como Latossolo Roxo distrófico, com as seguintes características: areia (13\%), silte (23\%), argila (64\%), M. ${ }^{\circ}$ $(2,5 \%)$ CTC $\left(10,1\right.$ eq.mg/100 $\left.\mathrm{cm}^{3}\right)$ e saturação de bases $(49 \%)$.

Utilizaram-se onze cultivares de cana-de-açúcar no estudo, sendo estas RB 72 454, RB 82 5336, RB 83 5089, RB 83 5486, RB 85 5035, RB 85 5156, SP 70 1143, SP 71 1406, SP 79 1011, SP 801842 e PO 8503. As cultivares foram implantadas no 
espaçamento de 1,40 m entrelinhas, sendo que todas as parcelas experimentais foram mantidas livre da presença da comunidade infestante através de capinas manuais.

Os tratamentos estudados foram diclosulam a $200 \mathrm{~g} \mathrm{ha}^{-1}$ aplicado em préemergência, diclosulam também a $200 \mathrm{~g} \mathrm{ha}^{-1}$ aplicado em pós-emergência e uma testemunha sem aplicação de herbicidas. As aplicações foram realizadas utilizando-se de um pulverizador costal a pressão constante de $\mathrm{CO}_{2}$ calibrado a $30 \mathrm{lb} / \mathrm{Pol}^{2}$ e equipado com barra de aplicação munida de pontas de jato plano tipo TeeJet 100.02. utilizou-se um consumo de calda de $200 \mathrm{~L} \mathrm{ha}^{-1}$. Por ocasião da aplicação do tratamento em préemergência, a temperatura e a umidade relativa do ar eram de $28^{\circ} \mathrm{C}$ e $58 \%$, respectivamente. Quando da aplicação do tratamento em pós-emergência, a temperatura e a umidade relativa do ar eram $27^{\circ} \mathrm{C}$ e $65 \%$, respectivamente. O vento apresentava-se em forma de rajada e oscilava entre 0,8 e $1,9 \mathrm{~m} \mathrm{~s}^{-1}$ durante a aplicação em préemergência; e entre 1,3 e $2,3 \mathrm{~m} \mathrm{~s}^{-1}$ durante a aplicação em pós-emergência. A soqueira da cana-de-açúcar (4ํㅜ ano) estava no estádio de "esporão" a uma folha, em média, por ocasião da aplicação em pós-emergência, o qual foi realizada oito dias após a aplicação de pré-emergência.

A seletividade dos tratamentos herbicidas às plantas de cana-de-açúcar foi avaliada visualmente através de uma escala de notas em porcentagem, onde "zero" correspondia a nenhuma injúria e "100" a morte de plantas. As avaliações visuais de injúria foram realizadas aos 35, 49, 64 e 89 DAA do herbicida, tanto em pré como em pós-emergência. Por ocasião da colheita, foram avaliados os seguintes parâmetros tecnológicos e produtivos da cultura da cana-de-açúcar: Pol (\%), Brix (\%), fibra (\%), diâmetro de colmos, número de colmos, comprimento de colmos e produtividade de colmos e açúcar.

Foi utilizado o delineamento experimental em blocos ao acaso em parcelas subdivididas, com quatro repetições. As variedades foram dispostas nas parcelas experimentais e os tratamentos herbicidas nas parcelas subdivididas. Cada parcela foi composta por cinco linhas de plantio por 7,0 $\mathrm{m}$ de comprimento, perfazendo um total de $49 \mathrm{~m}^{2}$.

Os dados bromatológicos e produtivos da cana-de-açúcar foram submetidos a análise de variância pelo teste $\mathbf{F}$ e as médias dos tratamentos foram comparadas pelo teste de Tukey a $5 \%$ de probabilidade.

\section{RESULTADOS E DISCUSSÃO}

$\mathrm{Na}$ Tabela 1 estão apresentadas as porcentagens de fitointoxicação visual nas diversas cultivares de cana-de-açúcar proporcionadas pelos tratamentos herbicidas, em diferentes períodos de avaliação após a aplicação. Todos os tratamentos herbicidas foram visualmente seletivos para nove das onze variedades de cana-de-açúcar estudadas. Apenas as variedades RB 855035 e RB 855156 apresentaram sintomas de intoxicação provocados pelo herbicida diclosulam, tanto na aplicação em pré como em pós-emergência. Os sintomas de injuria foram mais intensos na primeira avaliação realizada aos 35 dias após a aplicação (DAA), sendo que a intensidade oscilou com a cultivar de cana-de-açúcar estudada e com o modo de aplicação.

A cultivar RB 855035 mostrou ser mais sensível ao diclosulam, apresentando níveis de injuria de $8 \%$ e $15 \%$ para as aplicações feitas em pré e em pós-emergência, respectivamente. Já a cultivar RB 855156 apresentou níveis menores de intoxicação na ordem de $5 \%$ e $9 \%$ para as aplicações em pré e em pós-emergência, respectivamente. Nota-se também que as fitointoxicações proporcionadas pelas aplicações realizadas em 
pós-emergência foram ligeiramente mais intensas quando comparadas àquelas feitas em pré-emergência. Isto deve-se ao fato talvez ao maior contato entre o herbicida e a canade-açúcar e ao modo de aplicação. Porém, tais níveis de injuria observados nas duas cultivares são considerados como agronomicamente aceitáveis, pois normalmente não proporcionam danos econômicos às culturas (ALAM, 1974).

A velocidade de dissipação da fitointoxicação nas plantas de cana-de-açúcar também dependeu do genótipo estudado. Como ilustrado na Figura 1, a cultivar RB 85 5035 também destacou-se na velocidade de dissipação da fitointoxicação, mostrando recuperação de aproximadamente 50\% já na segunda avaliação feita aos 49 DAA, tanto para a aplicação em pré como em pós-emergência. A cultivar RB 85 5156, embora com menores níveis de fitointoxicação, apresentou menor velocidade de recuperação em relação à variedade RB85 5035, sendo que aos 49 DAA esta cultivar havia recuperado somente em 33,3\% da injúria inicial observada para a aplicação em pós-emergência. Os sintomas de fitointoxicação praticamente desapareceram na avaliação realizada aos 64 DAA nas duas cultivares de cana-de-açúcar que foram sensíveis ao herbicida diclosulam. Constantin et al. (2000), trabalhando com a cultivar SP 79 2233, relatam que o diclosulam, além de proporcionar injúrias mais intensas que os demais tratamentos, também apresentou tendência de diminuir o perfilhamento e a altura da cana-de-açúcar quando aplicado a 200 e $250 \mathrm{~g} \mathrm{ha}^{-1}$. Os autores também comentam que aos 170 DAA já não havia mais diferença significativa em relação ao padrão.

$\mathrm{Na}$ Tabela 2 estão apresentados os resultados do efeito das aplicações herbicida sobre os teores de Pol, Brix e fibra das diferentes cultivares de cana-de-açúcar testadas. Verifica-se que todos os parâmetros tecnológicos estudados das onze cultivares de canade-açúcar, como Pol, Brix e fibra, não foram influenciados de forma negativa pela aplicação do herbicida diclosulam, tanto em aplicação em pré como em pós-emergência. Ao contrario, os tratamentos herbicidas favoreceram o Pol\% das variedades RB 72454 e RB 83 5089, sendo que as plantas que receberam o herbicida diclosulam apresentaram valores maiores daqueles observados para a testemunha. Tal observação opõe-se a outro estudo, uma vez que pesquisas conduzidas por Montório et al. (2000) com a cultivar RB 835089 mostraram que tais características tecnológicas eram influenciadas de forma negativa pela aplicação de diversos herbicidas recomendados para a cultura, como ametryne, tebuthiuron, diuron+ametryne e oxyfluorfen

Os resultados do efeito das aplicações do herbicida sobre as características produtivas da cultura da cana-de-açúcar, como o diâmetro do colmo, comprimento de colmo, número de colmos/parcela e produtividade de colmos e açúcar estão apresentados na Tabela 3. Observa-se que todos os parâmetros produtivos da cultura também não foram influenciados de forma negativa pela aplicação do herbicida diclosulam, tanto em pré como em pós-emergência. Nota-se ainda que o número de colmos por parcela apresentou significância, porém os valores encontrados para as parcelas tratadas com o herbicida foram iguais ou superiores aos valores encontrados na testemunha. Cabe salientar que a área era de uma cana-soca de quatro anos, onde falhas na brotação ocorrem normalmente e que as diferenças encontradas no número de colmos por parcela foram compensadas talvez por um acúmulo maior de reservas nos colmos, como pode ser verificado no rendimento de colmos em $\mathrm{t} \mathrm{ha}^{-1}$, que apresentou produções semelhantes entre os três tratamentos testados nas onze cultivares de canade-açúcar estudadas avaliadas.

Apesar dos sintomas iniciais de fitointoxicação observados nas cultivares RB 85 5035 e RB 85 5156, o diclosulam, aplicado isoladamente em pré ou em pós-emergência, mostrou-se seletivo às onze variedades de cana-de-açúcar testadas quanto às características tecnológicas e produtivas. 


\section{LITERATURA CITADA}

ALAM - Asociacion Latinoamericana de Malezas. Recomendaciones sobre unificaión de los sistemas de evaluación en ensayos de control de malezas. Bogotá, v.1, n.1, p. 35-38, 1974.

CONSTANTIN, J. OLIVEIRA JR, R.S., FAGLIARI, J.R., MACIEL, C.D.G. Diclosulam: alternativa para o controle de Cyperus rotundus e Digitaria horizontalis na cultura da cana-de-açúcar. In: CONGRESSO BRASILEIRO DA CIÊNCIA DAS PLANTAS DANINHAS, 22ํㅡ, Foz de Iguaçú/PR, 2000a. Anais... p. 303.

CONSTANTIN, J., MACIEL, C.D.G., CONTIERO, R.L. Seletividade e eficiência do diclosulam, no controle de Brachiaria plantaginea e Ipomoea grandifolia na cultura da cana-de-açúcar. In: CONGRESSO BRASILEIRO DA CIÊNCIA DAS PLANTAS DANINHAS, 22ํㅡ, Foz de Iguaçú/PR, 2000b. Anais... p. 302.

MONTÓRIO, G.A., CONSTANTIN, J., VELENI, E.D., SOUZA, R.T. Avaliação de herbicidas sobre as características tecnológicas da cana-de-açúcar cv RB 835089 utilizando-se duas testemunhas laterais. In: CONGRESSO BRASILEIRO DA CIÊNCIA DAS PLANTAS DANINHAS, 22ํㅡㄹ Foz de Iguaçú/PR, 2000a. Anais... p. 325.

RODRIGUES, B.N., ALMEIDA, F.S. Guia de herbicidas. Ed. Autor, 1998. 648p. 
Tabela 1. Porcentagem média de fitointoxicação visual, em diversas cultivares de canade-açúcar, ocasionada por diclosulam aplicado em pré e pós-emergência, em diferentes períodos de avaliação. Barra Bonita-SP. 1998/99.

\begin{tabular}{|c|c|c|c|c|c|}
\hline \multirow[b]{2}{*}{ Cultivar } & \multirow[b]{2}{*}{ Condição Aplicação } & \multicolumn{4}{|c|}{ Dias após aplicação } \\
\hline & & 35 & 49 & 64 & 89 \\
\hline \multirow{3}{*}{ 1. RB 825336} & testemunha & - & - & - & - \\
\hline & pré-emergência ${ }^{1}$ & 0 & 0 & 0 & 0 \\
\hline & pós-emergência ${ }^{12}$ & 0 & 0 & 0 & 0 \\
\hline \multirow[t]{3}{*}{ 2. RB 72454} & testemunha & - & - & - & - \\
\hline & pré-emergência & 0 & 0 & 0 & 0 \\
\hline & pós-emergência & 0 & 0 & 0 & 0 \\
\hline \multirow[t]{3}{*}{ 3. SP 701143} & testemunha & - & - & - & - \\
\hline & pré-emergência & 0 & 0 & 0 & 0 \\
\hline & pós-emergência & 0 & 0 & 0 & 0 \\
\hline \multirow{3}{*}{ 4. RB 835089} & testemunha & - & - & - & - \\
\hline & pré-emergência & 0 & 0 & 0 & 0 \\
\hline & pós-emergência & 0 & 0 & 0 & 0 \\
\hline \multirow[t]{3}{*}{ 5. PO 8503} & testemunha & - & - & - & - \\
\hline & pré-emergência & 0 & 0 & 0 & 0 \\
\hline & pós-emergência & 0 & 0 & 0 & 0 \\
\hline \multirow{3}{*}{ 6. SP 711406} & testemunha & - & - & - & - \\
\hline & pré-emergência & 0 & 0 & 0 & 0 \\
\hline & pós-emergência & 0 & 0 & 0 & 0 \\
\hline \multirow[t]{3}{*}{ 7. RB 855035} & testemunha & - & - & - & - \\
\hline & pré-emergência & 8 & 5 & 0 & 0 \\
\hline & pós-emergência & 15 & 7 & 0 & 0 \\
\hline \multirow[t]{3}{*}{ 8. SP 791011} & testemunha & - & - & - & - \\
\hline & pré-emergência & 0 & 0 & 0 & 0 \\
\hline & pós-emergência & 0 & 0 & 0 & 0 \\
\hline \multirow[t]{3}{*}{ 9. RB 835486} & testemunha & - & - & - & - \\
\hline & pré-emergência & 0 & 0 & 0 & 0 \\
\hline & pós-emergência & 0 & 0 & 0 & 0 \\
\hline \multirow[t]{3}{*}{ 10. SP 801142} & testemunha & - & - & - & - \\
\hline & pré-emergência & 0 & 0 & 0 & 0 \\
\hline & pós-emergência & 0 & 0 & 0 & 0 \\
\hline \multirow[t]{3}{*}{ 11. RB 855156} & testemunha & - & - & - & - \\
\hline & pré-emergência & 5 & 4 & 1 & 0 \\
\hline & pós-emergência & 9 & 6 & 2 & 0 \\
\hline
\end{tabular}

$1 \underline{1}$ diclosulam a $200 \mathrm{~g} \mathrm{ha}^{-1} ; \underline{1}$ diclosulam a $200 \mathrm{~g} \mathrm{ha}^{-1}$ (esporão a uma folha) 
Tabela 2. Efeitos médios da aplicação de diclosulam sobre os teores de Pol, fibra e Brix, em porcentagem, em diversas cultivares de cana-de-açúcar. Barra BonitaSP. 1998/99.

\begin{tabular}{|c|c|c|c|c|c|}
\hline \multirow[b]{2}{*}{ Cultivar } & \multirow[b]{2}{*}{ Tratamento } & \multicolumn{4}{|c|}{ Teores (\%) } \\
\hline & & Pol & Fibra & & Brix \\
\hline \multirow[t]{3}{*}{ 1. RB 825336} & testemunha & 13,96 & 19,74 & 20,60 & \\
\hline & pré-emergência ${ }^{1}$ & 13,79 & 18,98 & 20,53 & \\
\hline & pós-emergência ${ }^{12}$ & 13,88 & 19,41 & 21,03 & \\
\hline \multirow[t]{3}{*}{ 2. RB 72454} & testemunha & $14,32 \mathrm{~B}$ & 18,71 & 21,63 & \\
\hline & pré-emergência & $15,65 \mathrm{~A}$ & 15,80 & 22,27 & \\
\hline & pós-emergência & $14,89 \mathrm{AB}$ & 17,29 & 21,47 & \\
\hline \multirow[t]{3}{*}{ 3. SP 701143} & testemunha & 13,64 & 18,42 & 20,20 & \\
\hline & pré-emergência & 13,56 & 17,89 & 20,10 & \\
\hline & pós-emergência & 13,49 & 18,21 & 20,00 & \\
\hline \multirow[t]{3}{*}{ 4. RB 835089} & testemunha & $13,45 \mathrm{~B}$ & 19,98 & 20,57 & \\
\hline & pré-emergência & $14,56 \mathrm{~A}$ & 18,07 & 21,57 & \\
\hline & pós-emergência & $14,61 \mathrm{~A}$ & 18,47 & 21,67 & \\
\hline \multirow[t]{3}{*}{ 5. PO 8503} & testemunha & 13,95 & 19,49 & 21,57 & \\
\hline & pré-emergência & 14,08 & 18,90 & 21,40 & \\
\hline & pós-emergência & 14,38 & 18,45 & 21,37 & \\
\hline \multirow[t]{3}{*}{ 6. SP 711406} & testemunha & 13,38 & 20,02 & 20,63 & \\
\hline & pré-emergência & 14,11 & 19,23 & 21,10 & \\
\hline & pós-emergência & 13,82 & 19,74 & 20,50 & \\
\hline \multirow[t]{3}{*}{ 7. RB 855035} & testemunha & 14,98 & 16,98 & 21,70 & \\
\hline & pré-emergência & 15,02 & 17,65 & 21,73 & \\
\hline & pós-emergência & 14,19 & 17,72 & 20,77 & \\
\hline \multirow[t]{3}{*}{ 8. SP 791011} & testemunha & 14,72 & 17,74 & 21,27 & \\
\hline & pré-emergência & 14,16 & 17,66 & 20,63 & \\
\hline & pós-emergência & 14,10 & 18,98 & 20,67 & \\
\hline \multirow[t]{3}{*}{ 9. RB 835486} & testemunha & 14,91 & 19,50 & 21,53 & \\
\hline & pré-emergência & 14,81 & 19,20 & 21,70 & \\
\hline & pós-emergência & 15,46 & 17,13 & 22,07 & \\
\hline \multirow[t]{3}{*}{ 10. SP 801142} & testemunha & 15,47 & 17,73 & 22,10 & \\
\hline & pré-emergência & 15,27 & 17,49 & 21,97 & \\
\hline & pós-emergência & 15,46 & 16,95 & 22,27 & \\
\hline \multirow[t]{6}{*}{ 11. RB 855156} & testemunha & 16,32 & 16,75 & 22,57 & \\
\hline & pré-emergência & 15,53 & 17,50 & 22,23 & \\
\hline & pós-emergência & 16,03 & 16,86 & 22,83 & \\
\hline & Bloco & $0,90^{\mathrm{NS}}$ & $4,24 *$ & $0,14^{\mathrm{NS}}$ & \\
\hline & Cultivar (C) & $17,00 * *$ & $4,32 * *$ & $16,76^{*}$ & \\
\hline & Tratamento $(\mathrm{T})$ & $0,74^{\mathrm{NS}}$ & $1,73^{\mathrm{NS}}$ & $0,26^{\mathrm{NS}}$ & \\
\hline \multirow[t]{12}{*}{ Valores de F: } & $\mathrm{C} \times \mathrm{T}$ & $2,21 * *$ & $0,97^{\mathrm{NS}}$ & $1,56^{\mathrm{NS}}$ & \\
\hline & RB 825336 & $0,10^{\mathrm{NS}}$ & - & & - \\
\hline & RB 72454 & $6,03 *$ & - & & - \\
\hline & SP 701143 & $0,80^{\mathrm{NS}}$ & - & & - \\
\hline & RB 835089 & $5,79 * *$ & - & & - \\
\hline & PO 8503 & $0.64^{\mathrm{NS}}$ & - & & - \\
\hline & SP 711406 & $1,80^{\mathrm{NS}}$ & - & & - \\
\hline & RB 855035 & $2,92^{\mathrm{NS}}$ & - & & - \\
\hline & SP 791011 & $1,53^{\mathrm{NS}}$ & - & & - \\
\hline & RB 835486 & $1,64^{\mathrm{NS}}$ & - & & - \\
\hline & SP 801842 & $0,18^{\mathrm{NS}}$ & - & & - \\
\hline & RB 855156 & $2,16^{\mathrm{NS}}$ & - & & - \\
\hline \multirow[t]{2}{*}{ C.V. (\%) } & Cultivar & 4,3 & 7,0 & 2,4 & \\
\hline & Tratamento & 3,7 & 6,7 & 2,4 & \\
\hline
\end{tabular}

$\underline{1}$ diclosulam a $200 \mathrm{~g} \mathrm{ha}^{-1} ; \underline{2}$ diclosulam a $200 \mathrm{~g} \mathrm{ha}^{-1}$ (esporão a uma folha). 
Tabela 3. Efeitos médios de diferentes tratamentos químicos sobre diversos parâmetros produtivos da cultura de cana-de-açúcar. Barra Bonita-SP. 1998/99.

\begin{tabular}{|c|c|c|c|c|c|c|}
\hline Cultivar & Tratamento & $\begin{array}{c}\text { Diâmetro } \\
\text { de colmo } \\
(\mathrm{mm})\end{array}$ & $\begin{array}{l}\text { Comp }^{\text {to }} \\
\text { de colmo } \\
(\mathrm{m})\end{array}$ & $\begin{array}{c}\text { Número } \\
\text { de colmos } \\
\text { (parcela) }\end{array}$ & $\begin{array}{c}\text { Rendimento } \\
\text { de colmos } \\
\left(\mathrm{t} \mathrm{ha}^{-1}\right)\end{array}$ & $\begin{array}{c}\text { Rend }{ }^{\text {to }} \\
\text { de açúcar } \\
\left(\mathrm{kg} \mathrm{ha}^{-1}\right)\end{array}$ \\
\hline \multirow[t]{3}{*}{ RB 825336} & testemunha & 18,2 & 1,79 & $534 \mathrm{~B}$ & 63,41 & 8857 \\
\hline & pré-emergência ${ }^{\backslash 1}$ & 18,1 & 1,75 & $592 \mathrm{~B}$ & 70,07 & 9658 \\
\hline & pós-emergência ${ }^{12}$ & 18,6 & 1,74 & $679 \mathrm{~A}$ & 75,92 & 10300 \\
\hline \multirow[t]{3}{*}{ RB 72454} & testemunha & 22,2 & 1,65 & $431 \mathrm{AB}$ & 67,46 & 9718 \\
\hline & pré-emergência & 22,2 & 1,74 & $383 \mathrm{~B}$ & 64,57 & 10329 \\
\hline & pós-emergência & 21,8 & 1,64 & $467 \mathrm{~A}$ & 78,82 & 11736 \\
\hline \multirow[t]{3}{*}{ SP 701143} & testemunha & 16,7 & 1,44 & $527 \mathrm{~B}$ & 53,75 & 7361 \\
\hline & pré-emergência & 17,9 & 1,51 & $586 \mathrm{AB}$ & 61,90 & 8394 \\
\hline & pós-emergência & 16,3 & 1,50 & $638 \mathrm{~A}$ & 61,38 & 8282 \\
\hline \multirow[t]{3}{*}{ RB 835089} & testemunha & 19,5 & 1,93 & $490 \mathrm{~B}$ & 78,68 & 10654 \\
\hline & pré-emergência & 19,7 & 2,00 & $523 \mathrm{AB}$ & 80,72 & 11772 \\
\hline & pós-emergência & 18,3 & 1,92 & $567 \mathrm{~A}$ & 90,27 & 13205 \\
\hline \multirow[t]{3}{*}{ PO 8503} & testemunha & 18,4 & 1,24 & $578 \mathrm{~B}$ & 53,16 & 7422 \\
\hline & pré-emergência & 19,5 & 1,30 & $586 \mathrm{~B}$ & 57,20 & 8112 \\
\hline & pós-emergência & 18,6 & 1,29 & $669 \mathrm{~A}$ & 63,55 & 9144 \\
\hline \multirow[t]{3}{*}{ SP 711406} & testemunha & 18,7 & 1,44 & 343 & 41,38 & 5303 \\
\hline & pré-emergência & 17,9 & 1,45 & 372 & 39,55 & 5698 \\
\hline & pós-emergência & 20,7 & 1,38 & 325 & 41,63 & 5642 \\
\hline \multirow[t]{3}{*}{ RB 855035} & testemunha & 19,4 & 1,78 & 451 & 62,54 & 9355 \\
\hline & pré-emergência & 19,7 & 1,82 & 462 & 62,36 & 9347 \\
\hline & pós-emergência & 20,1 & 1,83 & 511 & 32,68 & 8887 \\
\hline \multirow[t]{3}{*}{ SP 791011} & testemunha & 19,9 & 1,59 & $421 \mathrm{AB}$ & 56,73 & 9347 \\
\hline & pré-emergência & 20,5 & 1,50 & $402 \mathrm{~B}$ & 57,88 & 8205 \\
\hline & pós-emergência & 20,4 & 1,52 & $482 \mathrm{~A}$ & 65,83 & 9583 \\
\hline \multirow[t]{3}{*}{ RB 835486} & testemunha & 21,3 & 1,76 & $346 \mathrm{~B}$ & 63,33 & 9579 \\
\hline & pré-emergência & 20,9 & 1,75 & $419 \mathrm{~A}$ & 64,79 & 9602 \\
\hline & pós-emergência & 20,8 & 1,78 & $464 \mathrm{~A}$ & 69,10 & 10679 \\
\hline \multirow[t]{3}{*}{ SP 801142} & testemunha & 18,4 & 2,05 & $450 \mathrm{~B}$ & 67,24 & 10405 \\
\hline & pré-emergência & 17,8 & 2,12 & $490 \mathrm{AB}$ & 74,10 & 11315 \\
\hline & pós-emergência & 17,4 & 1,96 & $528 \mathrm{~A}$ & 73,43 & 11365 \\
\hline \multirow[t]{6}{*}{ RB 855156} & testemunha & 17,8 & 1,66 & $536 \mathrm{~B}$ & 57,27 & 9191 \\
\hline & pré-emergência & 18,0 & 1,67 & $568 \mathrm{~B}$ & 57,36 & 8933 \\
\hline & pós-emergência & 18,2 & 1,67 & $652 \mathrm{~A}$ & 70,84 & 11342 \\
\hline & Bloco & $10,90 * *$ & $5,33 * *$ & $1,57^{\mathrm{NS}}$ & $0,52^{\mathrm{NS}}$ & $0,40^{\mathrm{NS}}$ \\
\hline & Cultivar (C) & $4,14 * *$ & $57,81 * *$ & $28,23 * *$ & $23,93 * *$ & $20,62 * *$ \\
\hline & Tratamento $(\mathrm{T})$ & $0,90^{\mathrm{NS}}$ & $2,51^{\mathrm{NS}}$ & $49,12 * *$ & $20,63 * *$ & $18,53 * *$ \\
\hline \multirow[t]{12}{*}{ Valores de F: } & $\mathrm{C} \times \mathrm{T}$ & $1,12^{\mathrm{NS}}$ & $1,10^{\mathrm{NS}}$ & $2,12 * *$ & $1,06^{\mathrm{NS}}$ & $1,20^{\mathrm{NS}}$ \\
\hline & RB 825336 & - & - & $13,76 * *$ & - & - \\
\hline & RB 72454 & - & - & $4,64 *$ & - & - \\
\hline & SP 701143 & - & - & $8,05 * *$ & - & - \\
\hline & RB 835089 & - & - & $3,85 *$ & - & - \\
\hline & PO 8503 & - & - & $8,68 * *$ & - & - \\
\hline & SP 711406 & - & - & $1,48^{\mathrm{NS}}$ & - & - \\
\hline & RB 855035 & - & - & $2,67^{\mathrm{NS}}$ & - & - \\
\hline & SP 791011 & - & - & $4,52 *$ & - & - \\
\hline & RB 835486 & - & - & $9,38 * *$ & - & - \\
\hline & SP 801842 & - & - & $3,92 *$ & - & - \\
\hline & RB 855156 & - & - & $9,38 * *$ & - & - \\
\hline \multirow[t]{2}{*}{ C.V. (\%) } & Cultivar & 10,01 & 14,3 & 101,6 & 11,1 & 14,1 \\
\hline & Tratamento & 6,2 & 9,8 & 7,9 & 9,6 & 10,5 \\
\hline
\end{tabular}

$\underline{1}$ diclosulam a $200 \mathrm{~g} \mathrm{ha}^{-1} ; \underline{2}$ diclosulam a $200 \mathrm{~g} \mathrm{ha}^{-1}$ (esporão a uma folha). 

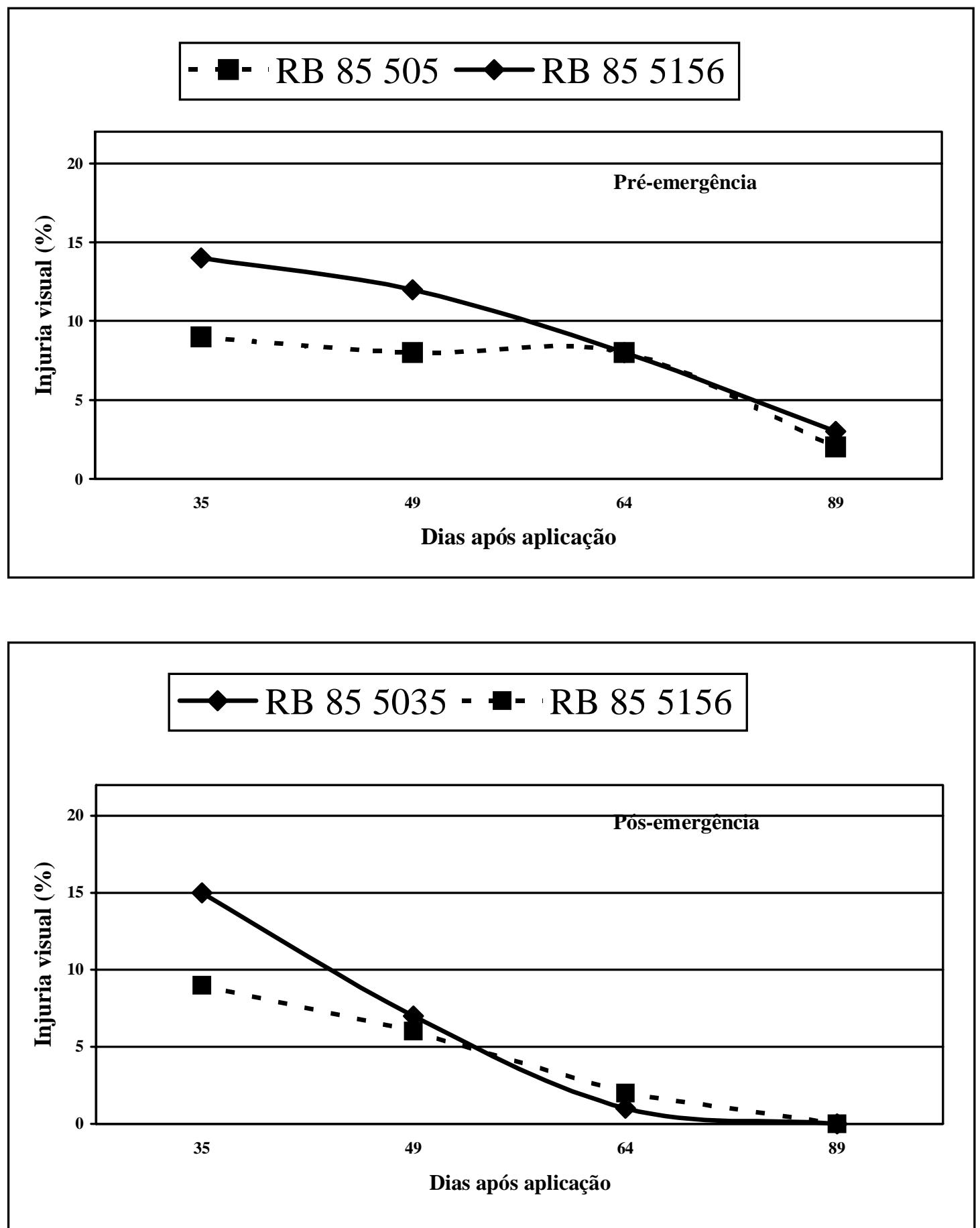

Figura 1. Gráfico representativo das velocidades de recuperação das duas cultivares mais sensíveis aos tratamentos herbicidas. Barra Bonita-SP. 1998/99. 